in vivo $34: 1009-1016(2020)$

doi:10.21873/invivo.11869

\title{
Augmentation of Neurotoxicity of Anticancer Drugs by X-Ray Irradiation
}

\author{
GIICHIROU NAKAYA ${ }^{1}$, HIROSHI SAKAGAMI ${ }^{2}$, YUKARI KOGA-OGAWA ${ }^{1}$, AKIYOSHI SHIROTO ${ }^{1}$, \\ TADAMASA NOBESAWA ${ }^{1}$, DAISUKE UEDA ${ }^{1}$, SACHIE NAKATANI ${ }^{3}$, KENJI KOBATA ${ }^{3}$, YOSUKE IIJIMA ${ }^{4}$, \\ SHIGENOBU TONE ${ }^{5}$, ANGEL DAVID-GONZALEZ ${ }^{6}$, RENE GARCIA-CONTRERAS ${ }^{6}$, \\ MINEKO TOMOMURA ${ }^{2}$, SHINJI KITO ${ }^{2}$, NOBUAKI TAMURA ${ }^{2}$ and HIROSHI TAKESHIMA ${ }^{2}$ \\ ${ }^{1}$ Faculty of Health Sciences, Nihon Institute of Medical Science, Saitama, Japan; \\ ${ }^{2}$ Meikai University School of Dentistry, Saitama, Japan; \\ ${ }^{3}$ Graduate School of Pharmaceutical Sciences, Josai University, Saitama, Japan; \\ ${ }^{4}$ Saitama Medical Center, Saitama Medical University, Saitama, Japan; \\ ${ }^{5}$ Graduate School of Science and Engineering, Tokyo Denki University, Saitama, Japan; \\ ${ }^{6}$ National School of Higher Education, Leon Unit, National Autonomous University of Mexico, Mexico City, Mexico
}

\begin{abstract}
Background: In order to investigate the combination effect of anticancer drugs and X-ray irradiation on neurotoxic side-effects (neurotoxicity), a method that provides homogeneously X-ray-irradiated cells was newly established. Materials and Methods: PC12 cell suspension was irradiated by $X$-ray $(0.5 \mathrm{~Gy})$ in serum-supplemented medium, immediately inoculated into 96-microwell plates and incubated overnight. The medium was replaced with fresh serum-depleted medium containing $50 \mathrm{ng} / \mathrm{ml}$ nerve growth factor to induce differentiation toward nerve-like cells with characteristic neurites according to the overlay method without changing the medium. The differentiated cells were treated by anticancer drugs as well as antioxidants, oxaliplatin or bortezomib, and the viable cell number was determined by 3-(4,5-dimethylthiazol-2-yl)-2,5diphenyltetrazolium bromide method. Results: Antioxidants and anticancer drugs were cytotoxic to differentiating PC12 cells. Combination of anticancer drugs and X-ray irradiation slightly reduced cell viability. Conclusion: The present 'population irradiation method' may be useful for the investigation of the combination effect of $X$-ray irradiation and any pharmaceutical drug.
\end{abstract}

This article is freely accessible online.

Correspondence to: Professor Hiroshi Sakagami, Meikai University Research Institute of Odontology, 1-1 Keyakidai, Sakado, Saitama 350-0283, Japan. E-mail: sakagami@dent.meikai.ac.jp

Key Words: X-Ray irradiation, PC12, NGF, neurotoxicity, protective effect.
$\mathrm{X}$-Rays are used for many purposes in various fields. This includes the visualization of the distribution and therapeutic effects of drugs by X-ray computed tomography (1); the assessment of chemical element changes by energy dispersive $\mathrm{X}$-ray spectrometry (2); the analysis of crystal structure by Xray diffraction (3); the analysis of oral mucosal distribution of trace metal elements by X-ray fluorescence with synchrotron radiation and particle-induced X-ray emission, and the estimation of chemical states of elements by X-ray absorption fine-structure analysis (4); the visual inspection of passenger baggage in airports by X-ray images (5); and therapeutic applications in medicine (6). Radiation, such as X-rays, and drugs, are reported to exert dose-dependent biphasic effects (7).

X-Ray irradiation has been reported to stimulate the production of reactive oxygen-species such as superoxide and nitrite $(8,9)$, the secretion of Fas ligand $(10)$, the accumulation of cells in the $\mathrm{G}_{2}+\mathrm{M}$ phase in the cell cycle (11), and the shortening of telomeres (12). On the other hand, at lower doses of X-irradiation, beneficial effects (known as hormesis) can be induced. For example, Xirradiation at $10 \mathrm{mGy}$ (but not 50 or $100 \mathrm{mGy}$ ) reduced the frequency of micronucleated cells in human lymphocytes to below the spontaneous level (13).

Recently, we discovered that among anticancer drugs, platinum preparations (cisplatin, carboplatin, oxaliplatin) and proteasome inhibitor bortezomib showed potent cytotoxicity not only against normal oral keratinocytes (14) but also against PC12 nerve-like cells (Iijima et al., unpublished data). The neurotoxicity of anticancer agents and X-ray irradiation is a recent research topic in today's aging society. In the present study, we investigated whether cytotoxic doses of X-ray irradiation further augment neurotoxicity induced by oxaliplatin and bortezomib. To perform this experiment, 


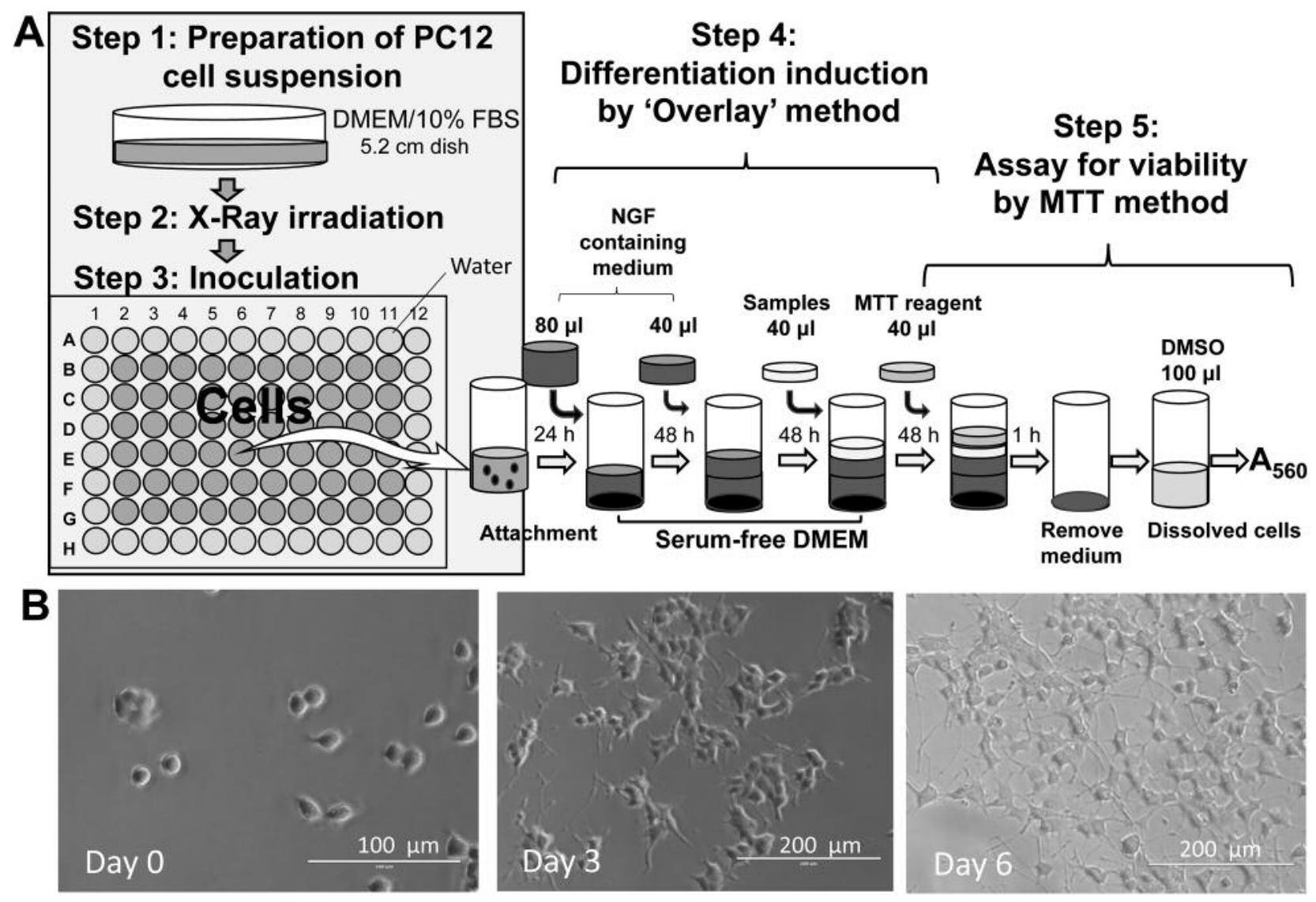

Figure 1. Population irradiation method used for the X-ray irradiation and induction of differentiation of PC12 cells. A: Five steps for measuring $X$-ray-induced cytotoxicity. B: Morphological changed induced by nerve growth factor (NGF; $50 \mathrm{ng} / \mathrm{ml})$ in serum-free medium. DMEM: Dulbecco's modified Eagle's medium; FBS: fetal bovine serum; MTT: 3-(4,5-dimethylthiazol-2-yl)-2,5-diphenyltetrazolium bromide.

A

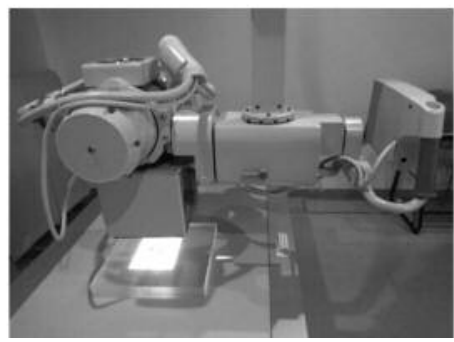

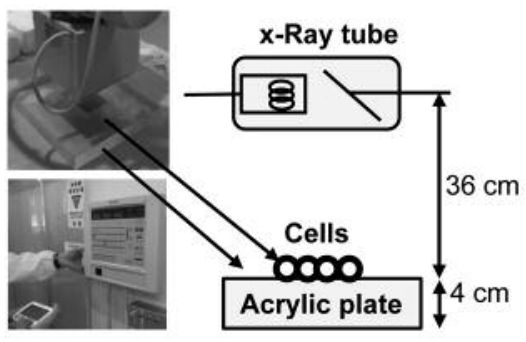

B

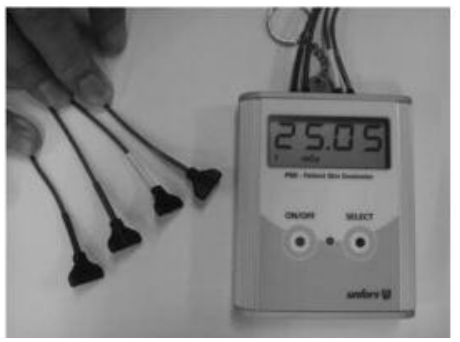

Figure 2. A: X-Ray apparatus and B: skin exposure dosimeter used in this study.

the anode heel effect of an X-ray tube that makes the cells on the anode side more susceptible to X-ray damage needs to be taken into consideration. Therefore, we first established a method which enabled the homogeneous irradiation of the cell population in each 96-microwell plate for anticancer drug treatment. This method, referred to as the 'population irradiation method', comprised five steps (Figure 1): (i) The preparation of a rat pheochromocytoma PC12 cell suspension; (ii) X-ray irradiation (Figure 2); (iii) inoculation and attachment in Dulbecco's modified Eagle's medium (DMEM) supplemented with 10\% fetal bovine serum (FBS); (iv) induction of neuronal differentiation by nerve growth factor (NGF) and addition of anticancer drugs in serum-free method; and (v) viability assay (Figure 1). 


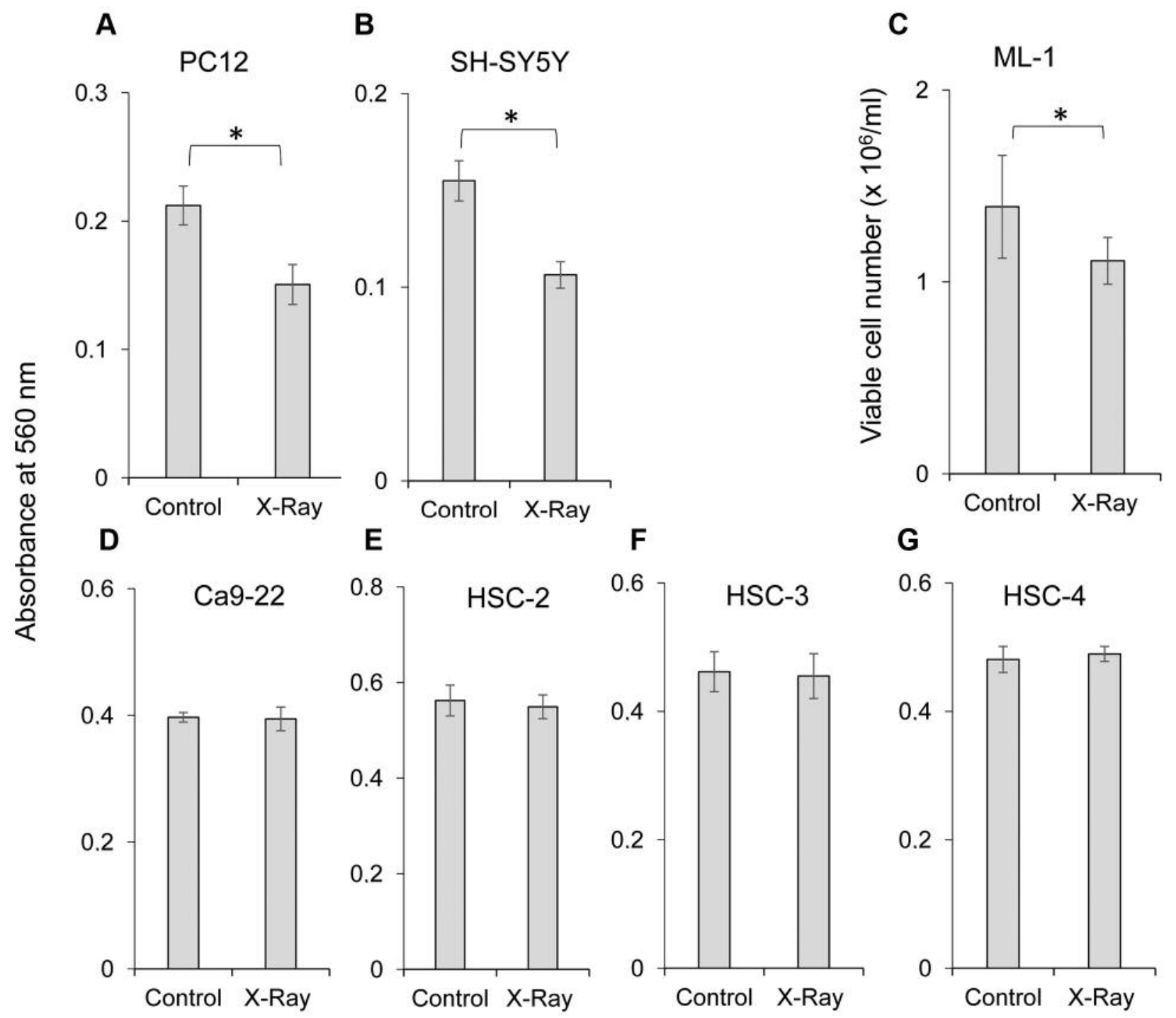

Figure 3. Comparison of X-ray sensitivity among several cultured cell lines. Near-confluent cells were exposed to 0 (control) or $505 \mathrm{mGy} X$-ray in Dulbecco's modified Eagle's medium (DMEM) supplemented with 10\% fetal bovine serum (FBS), and then incubated for 48 without changing the medium. The viable cell number was then determined by 3-(4,5-dimethylthiazol-2-yl)-2,5-diphenyltetrazolium bromide method and expressed as a percentage that of the control. Each value represents the mean \pm S.D. of six determinations. *Significantly different at $p<0.05$.

\section{Materials and Methods}

Materials. The following chemicals and reagents were obtained from the indicated companies: DMEM from GIBCO BRL (Grand Island, NY, USA); human recombinant NGF, chlorogenic acid and dimethyl sulfoxide from Wako Pure Chem. Ind. (Osaka, Japan); FBS and 3-(4,5-dimethylthiazol-2-yl)-2,5-diphenyltetrazolium bromide (MTT) from Sigma-Aldrich Inc. (St. Louis, MO, USA); sodium ascorbate and $N$-acetyl-L-cysteine (NAC) from Tokyo Chemical Industry Co., Ltd (Tokyo, Japan); bortezomib from Janssen Pharmaceutical K.K. (Tokyo, Japan); oxaliplatin from Yakult Honsha Co., Ltd. (Tokyo, Japan); and culture plastic dishes and 96-well plates from Techno Plastic Products AG (Trasadingen, Switzerland).
Cell culture. PC12, a rat pheochromocytoma cell line derived from adrenal medulla; SH-SY5Y, a human neuroblastoma cell line cloned from a human bone marrow biopsy-derived line called SK-N-SH; human myeloblastic leukemia (ML-1); and human oral squamous cell carcinoma (OSCC) cell lines [Ca9-22 (derived from gingival tissue), and HSC-2, HSC-3, and HSC-4 (derived from tongue)] were purchased from Riken Cell Bank (Tsukuba, Japan). PC12, SHSY5Y (15), Ca9-22, HSC-2, HSC-3 and HSC-4 cells (14) were grown at $37^{\circ} \mathrm{C}$ in DMEM supplemented with $10 \%$ heat-inactivated FBS, 100 units/ml, penicillin $\mathrm{G}$ and $100 \mu \mathrm{g} / \mathrm{ml}$ streptomycin under a humidified atmosphere with $5 \% \mathrm{CO}_{2}$, while ML-1 cells were cultured in RPMI-1640 supplemented with 10\% FBS and antibiotics (16). These cell lines were used for the comparison of X-ray sensitivity. 
A

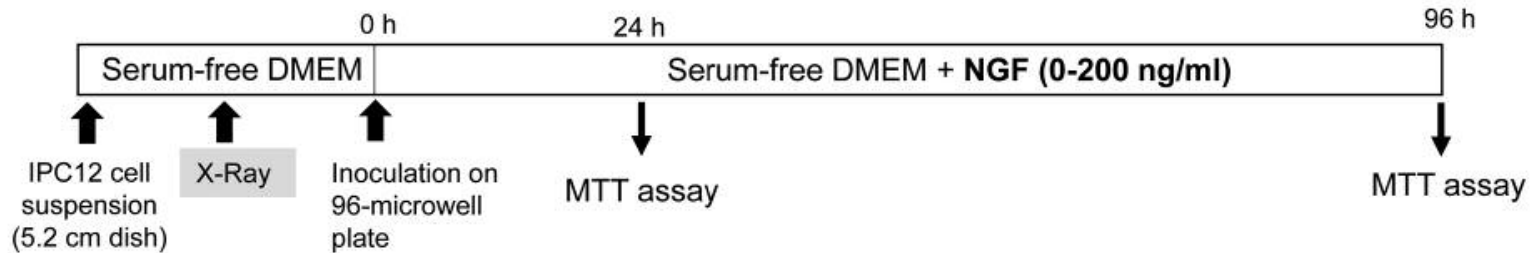
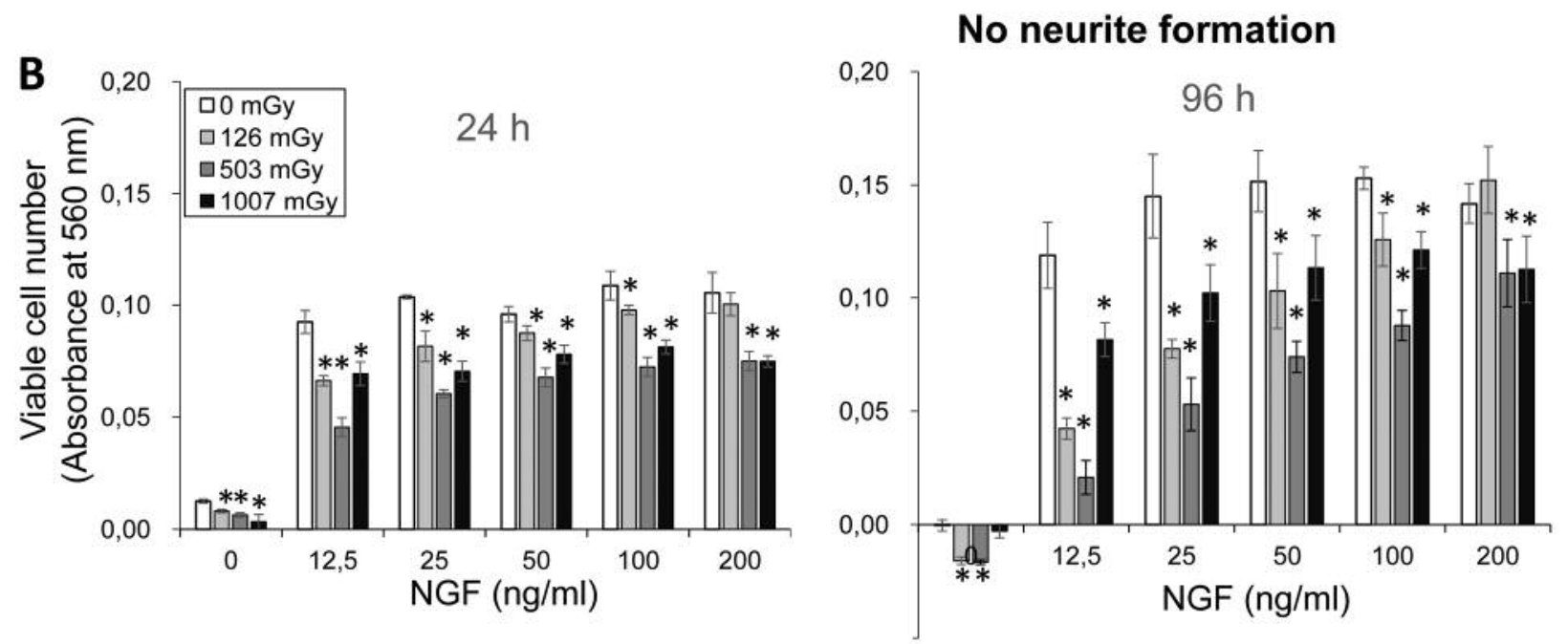

Figure 4. Protection by nerve growth factor (NGF) against X-ray-induced damage of PC12 cells. A: Experimental scheme. B: PC12 cells were seeded onto four $5.2 \mathrm{~cm}$ diameter dish [105 cells/5 ml of serum-free Dulbecco's modified Eagle's medium (DMEM)] and exposed to X-ray irradiation $(0,126,503$ or $1007 \mathrm{mGy})$. Immediately after the addition of 12.5, 25. 50, 100 or $200 \mathrm{ng} / \mathrm{ml} \mathrm{NGF}$, cells were incubated for 24 or $96 \mathrm{~h}$ in serumfree medium and the viable cell number was then determined by 3-(4,5-dimethylthiazol-2-yl)-2,5-diphenyltetrazolium bromide (MTT) method. Each value represents the mean $\pm S . D$. of five determinations. *Significantly different from the control at $p<0.0167$.

Induction of neuronal differentiation. $\mathrm{PC} 12$ cells were differentiated into maturing neuronal cells by the overlay method established in our laboratory (17). In brief, cultured PC12 cells were detached by trypsin, and the cell pellet after centrifugation was resuspended in serum-free or FBS (10\%)-supplemented DMEM. When cells were resuspended in serum-free medium, they were exposed to X-ray irradiation at 0 (control), 126, 503 or $1007 \mathrm{mGy}$, inoculated into 96microwell plates, and then 0 (control), 12.5, 25, 50, 100 or 200 $\mathrm{ng} / \mathrm{ml} \mathrm{NGF}$ was added in quintuplicate. When cells were resuspended in DMEM supplemented with $10 \%$ FBS, they were exposed to X-ray irradiation at 0 (control) or $506 \mathrm{mGy}$ and incubated for $24 \mathrm{~h}$ for cell attachment. The culture medium was then replaced with serum-free medium containing $50 \mathrm{ng} / \mathrm{ml} \mathrm{NGF}$ (differentiation medium) and incubated for 72, 96, 120 or $144 \mathrm{~h}$ with occasional NGF overlay in triplicate. Plates were not precoated with collagen-I, collagen-IV, nor with poly-L-lysine, since the overlay method reproducibly yielded the highest number of differentiated cells having characteristic neurites, possibly due to the endogenous production of survival and differentiation-inducing factor(s) (17). The extent of differentiation was assessed under light microscopy (EVOSfl; ThermoFisher Scientific, Waltham, MA, USA) $77,96,120$ or $144 \mathrm{~h}$ after NGF addition (18).

$X$-Ray irradiation. X-Ray irradiation was performed using a diagnostic X-ray apparatus (UD150L-30W; SHIMAZU, Kyoto, Japan) (Figure 2A). Culture plastic dishes or 96-well plates that contained cells were placed at the cathode side of an X-ray tube (SHIMAZU, P38DE 80s) on an acrylic plate (4 cm high) and irradiated with X-rays for 4, 8, 16 or 32 cycles of $0.2 \mathrm{~s}$ at $200 \mathrm{~mA}$ and $100 \mathrm{kV}$ (corresponding to 126 , 503 or 506 and $1007 \mathrm{mGy}$, respectively). Dosimetry was performed with a patient skin exposure dosimeter (Unfors Instruments Inc., New Milford, CT, USA) (Figure 2B). The measured value of the dose of $\mathrm{X}$-ray absorbed by the cells was corrected by multiplying the value obtained by exposure dosimeter with the correction factor.

Assay for viable cell number. The viable cell number of undifferentiated PC1 2 cells, OSCC and ML-1 cells were determined by removing the medium and then incubating for $2 \mathrm{~h}$ with $0.2 \mathrm{mg} / \mathrm{ml}$ MTT in fresh DMEM. The viability of differentiated PC12 cells were determined by overlaying a final concentration of $0.1 \mathrm{mg} / \mathrm{ml}$ MTT reagent (Figure 1) and incubating for $2 \mathrm{~h}$. The MTT-containing medium was then removed, and the purple crystals were lysed with $0.1 \mathrm{ml}$ of dimethyl sulfoxide. The relative viable cell number was determined from the absorbance of the cell lysate at $560 \mathrm{~nm}$, using a microplate reader (Infinite F50R; TECAN, Männedorf, Switzerland) (14).

In further experiments, the concentration of antioxidants (sodium ascorbate, NAC, chlorogenic acid) and anticancer drugs (oxaliplatin, bortezomib) that reduced the viable cell number by $50 \%\left(\mathrm{CC}_{50}\right)$ was determined from the dose-response curve in triplicate to sextuplicate.

Statistical treatment. Each value represents the mean \pm S.D. of 3-6 determinants. The statistical differences between control and X-rayirradiated groups were evaluated by paired or unpaired $t$-test. A 

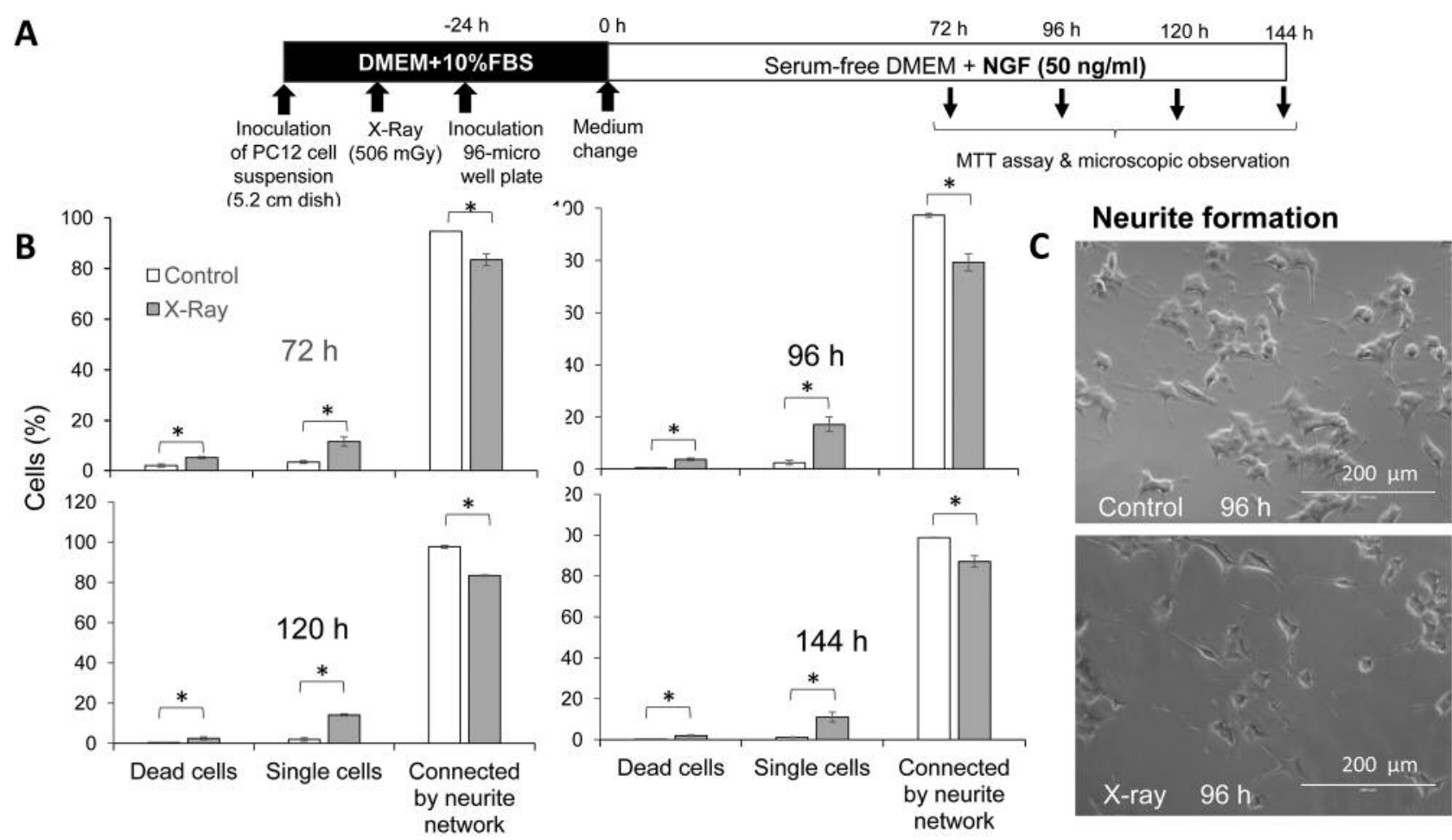

Figure 5. Disruption of connected neurite network by X-irradiation. A: Experimental scheme. B: PC12 cells were exposed to X-ray irradiation, inoculated and attached to 96-microwell plates, and incubated for $24 \mathrm{~h}$ to achieve cell attachment in Dulbecco's modified Eagle's medium (DMEM) supplemented with $10 \%$ fetal bovine serum (FBS). Culture medium was replaced with fresh serum-free medium containing $50 \mathrm{ng} / \mathrm{ml}$ nerve growth factor (NGF) and cells were further incubated for 72, 96, 120 or 144 h, and subjected to morphological observation. More than 400 cells were scored for classifying them as dead, single or cells connected by neurite network. Each value represents the mean \pm S.D. of three determinations. C: Representative cell morphology of control and X-ray-irradiated cells. MTT: 3-(4,5-Dimethylthiazol-2-yl)-2,5-diphenyltetrazolium bromide. *Significantly different at $p<0.05$.

value of $p<0.05$ was considered to be significant. Significance levels were recalculated by Bonferroni correction when X-ray-irradiated groups differed in radiation doses. Control and X-ray-irradiated groups were compared at each NGF concentration.

\section{Results}

High X-ray sensitivity of neuronal cells. Cells grown in 96microwell plates were irradiated by X-ray. When seven cell lines were subjected to X-ray irradiation ( $505 \mathrm{mGy}$ ), the viability of nerve precursor cells (rat pheochromocytoma cell line PC12, human neuroblastoma cell line SH-SY5Y) (Figure $3 \mathrm{~A}$ and $\mathrm{B}$ ) and human myeloblastic leukemia cells (ML-1) (Figure 3C) were significantly reduced, whereas those of the four OSCC cell lines (Ca9-22, HSC-2, HSC-3, HSC-4) were not affected (Figure 3D-G). Irradiation reduced the viable cell number of PC12, SH-SY5Y and ML-1 cells by $29 \%, 31 \%$ and 19\%, respectively (Figure 3A-C). Subsequent experiments used cells that had been preirradiated by X-ray using the 'population irradiation method' to provide homogeneously irradiated cells.
X-Ray-induced cytotoxicity in PC12 cells by NGF. When PC12 cells were incubated with serum-free medium (Figure 4A), the cell growth stopped within $24 \mathrm{~h}$. Addition of NGF stimulated cell growth (Figure 4B), confirming our previous report (17). $\mathrm{X}$-Ray irradiation before NGF addition reduced the viable cell number in most combinations (Figure 4B). The viable cell number of X-ray-treated (126 mGy) cells with NGF (200 $\mathrm{ng} / \mathrm{ml}$ ) was not significantly different from that of the control. It was unexpected that there was no neurite growth (data not shown). This problem was solved by the addition of FBS (10\%) during the cell-attachment period (Figure 5A), as judged from the presence of elongating neurites (Figure 5B and C).

Effect of X-ray irradiation on neurotoxicity of antioxidant and anticancer drugs by $X$-ray irradiation. X-Ray irradiation produced significantly higher numbers of dead and single cells and lower degree of neurite network formation (Figure 5B). Antioxidants (sodium ascorbate, NAC, chlorogenic acid) and anticancer drugs (oxaliplatin, bortezomib) showed cytotoxicity against differentiating PC12 cells with $\mathrm{CC}_{50}$ values of $0.36 \mathrm{mM}, 7.9 \mathrm{mM}, 0.43 \mathrm{mM}, 4.3 \mu \mathrm{g} / \mathrm{ml}$ and 0.45 


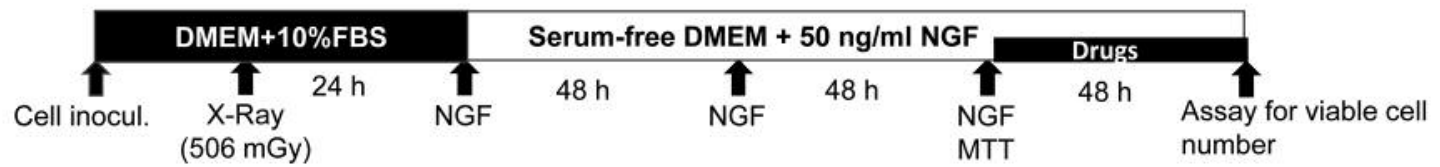

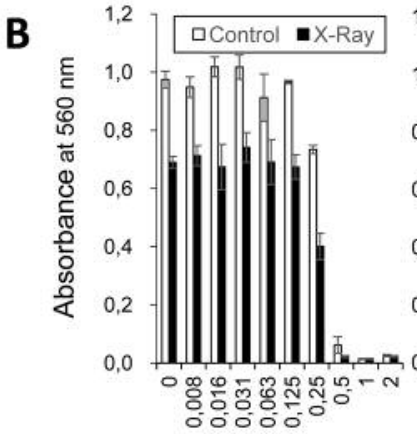

Sodium ascorbate $(\mathrm{mM})$

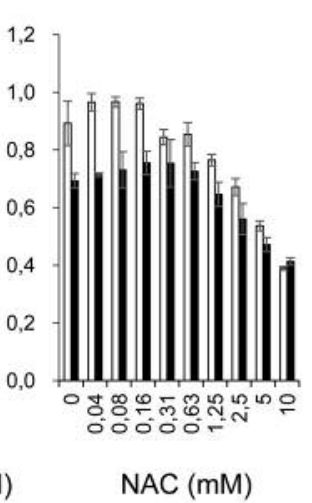

$\mathrm{NAC}(\mathrm{mM})$

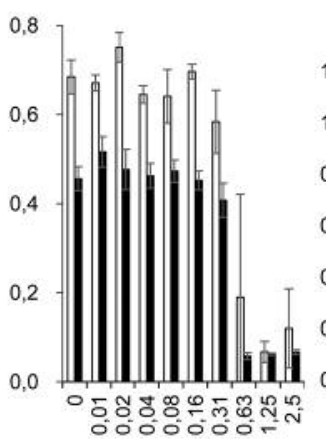

Chlorogenic acid $(\mathrm{mM})$

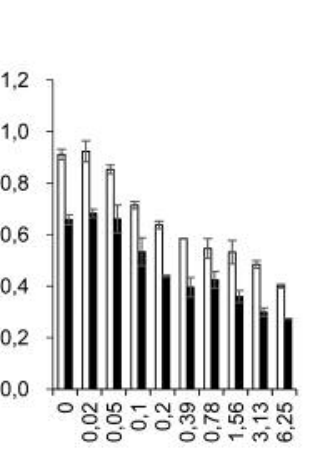

Oxaliplatin $(\mu \mathrm{g} / \mathrm{ml})$

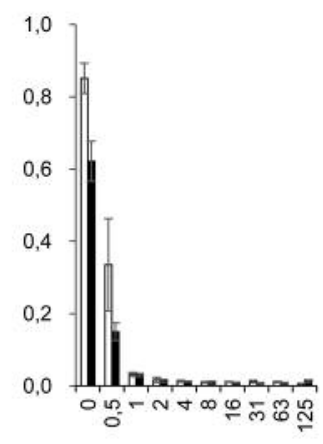

Bortezomib (ng/ml)

Figure 6. Augmentation of neurotoxicity of X-ray irradiation by antioxidants and anticancer drugs. A: Experimental scheme. B: PC12 cells were first exposed to X-ray irradiation ( $500 \mathrm{mGy}$ ) and induced to differentiated into nerve-like cells by NGF, and then treated with antioxidants sodium ascorbate, $N$-acetyl-L-cysteine (NAC), or chlorogenic acid, or anticancer drugs oxaliplatin, or bortezomib. Viable cells were then determined by $3-$ (4,5-dimethylthiazol-2-yl)-2,5-diphenyltetrazolium bromide (MTT) method. Each value represents the mean \pm S.D. of six determinations. DMEM: Dulbecco's modified Eagle's medium; FBS: fetal bovine serum; NGF: nerve growth factor.

Table I. Sensitivity of X-ray-irradiated cells to anticancer drugs. Data of control and X-ray-irradiated differentiated PC12 cells were derived from Figure 6. Data of oral squamous cell carcinoma (OSCC) and human normal oral cells [human gingival fibroblast (HGF), human periodontal ligament fibroblast (HPLF), human pulp cell (HPC)] were derived from our recent article (14).

\begin{tabular}{|c|c|c|c|c|c|c|c|c|c|c|c|}
\hline \multirow[b]{3}{*}{ Agent } & \multicolumn{11}{|c|}{$\mathrm{CC}_{50}$} \\
\hline & \multicolumn{2}{|c|}{ Differentiated PC12 cells } & \multicolumn{5}{|c|}{ OSCC cells } & \multicolumn{4}{|c|}{ Human normal oral cells } \\
\hline & Control & X-Ray-irradiated & $\mathrm{Ca} 9-22$ & HSC-2 & HSC-3 & HSC-4 & Mean & HGF & HPLF & HPC & Mean \\
\hline $\begin{array}{l}\text { Oxaliplatin } \\
(\mu \mathrm{g} / \mathrm{ml})\end{array}$ & $4.3(100)$ & $1.4(33)$ & 6.6 & 3.6 & 2.5 & 4.6 & $4.3(100)$ & 31.1 & 30.5 & 26.5 & $29.4(683)$ \\
\hline $\begin{array}{l}\text { Bortezomib } \\
(\mathrm{ng} / \mathrm{ml})\end{array}$ & $0.45(100)$ & $0.42(93)$ & 0.98 & 0.98 & 0.98 & 1.3 & $1.06(236)$ & 27 & 1800 & 150 & $659(146444)$ \\
\hline
\end{tabular}

The number in parentheses indicates the percentage change relative to that of the PC12 control.

$\mathrm{ng} / \mathrm{ml}$, respectively (Figure 6B). X-Ray irradiation at 506 mGy reduced cell viability by $29 \%, 22 \%, 33 \%, 27 \%$ and $27 \%$, respectively. Combination of X-ray irradiation with sodium ascorbate, chlorogenic acid, oxaliplatin or bortezomib slightly reduced the $\mathrm{CC}_{50}$ value to $0.27 \mathrm{mM}$, $0.35 \mathrm{mM}, 1.4 \mu \mathrm{g} / \mathrm{ml}$ and $0.42 \mathrm{ng} / \mathrm{ml}$, inducing an increase of neurotoxicity by 1.3-, 1.2-, 3.1- and 1.1-fold, respectively.

\section{Discussion}

In this study, we first established the optimal conditions for Xray irradiation of differentiating PC12 cells. We selected PC12 cells as a model system since (i) the viability of this cell line and SH-SY5Y (another popular cell line used in neuroscience) were significantly reduced by X-ray irradiation (Figure 3), and (ii) this cell line can be differentiated by NGF into nerve-like cells characterized by neurites (17). We found that the optimal dose of X-ray irradiation was $0.5 \mathrm{~Gy}$, nearly two orders lower than that used for cancer treatment of papillary tumor (45 to $60 \mathrm{~Gy}$ for 3D conformal radiation therapy and from 12 to 36 Gy for stereotactic radiosurgery) (19) and locally advanced cervical cancer (45 to 50.4 Gy) (20). NGF stimulated PC12 cell growth in serum-free medium, however, X-ray irradiation reduced the viable cell number under most combinations of 
irradiation dose and NGF concentration, even in the presence of NGF (Figure 4). It was unexpected that FBS needed to be present during the cell-attachment period ( $24 \mathrm{~h})$ after X-ray irradiation. Cell attachment in the absence of FBS completely inhibited the formation of neurites by an as yet unidentified mechanism. It remains to be investigated whether NGF stimulates the growth of the cells remaining after X-ray irradiation or inhibits cell death induced by X-ray irradiation.

The present study demonstrated that X-ray irradiation significantly reduced the viability of two neuronal cell lines (undifferentiated PC12, and SH-SY5Y) and human myeloblastic leukemia cell line ML-1, but not that of four OSCC cell lines (Ca9-22, HSC-2, HSC-3, HSC-4) (Figure 3). When we compared these with our previous data (14), differentiated PC12 cells showed much higher sensitivity to two popular anticancer drugs (oxaliplatin, bortezomib) as compared with four OSCC cell lines and human normal oral cells (Table I). The sensitivity of differentiated PC12 cells against oxaliplatin was calculated to be 1.0- and 6.8-fold higher than that of OSCC and normal cells, respectively. Similarly, the sensitivity of differentiated PC12 cells against bortezomib was 2.4- and 1464-fold higher than that of OSCC and normal cells, respectively (Table I). The sensitivity of differentiated PC12 cells was further augmented by X-ray treatment. This suggests the necessity of cautional use of the combination of $\mathrm{X}$-ray irradiation and classical anticancer drug (oxaliplatin) and proteasome inhibitor (bortezomib) for the treatment of cancer.

We found that X-rays did not in fact enhance but rather reduced the cytotoxicity of NAC. This may be due to the relatively lower cytotoxicity of NAC, necessitating the use of a higher concentration to induce cytotoxicity. This clearly reduced the $\mathrm{pH}$ in the culture medium due to its acidic property, possibly having affected the cellular metabolism.

It remains to be investigated whether reactive oxygen species may be involved in the combinational treatment of $\mathrm{X}$-ray and radiotherapy $(21,22)$. We also found that the cytotoxicity of X-ray irradiation was also enhanced by sodium ascorbate and chlorogenic acid, well-known antioxidants. This suggests a common mechanism of the augmentation of anticancer activity of X-rays, regardless of the accompanying compound.

\section{Conflicts of Interest}

The Authors wish to confirm that there are no known conflicts of interest associated with this publication and there has been no significant financial support for this work that could have influenced its outcome.

\section{Authors' Contributions}

G.N., N.T., H.T established X-ray irradiation method and protocol. H.S., Y.I., Y.K-O., T.N., D.U., A.S and A. D-G performed X-ray irradiation and cytotoxicity assay and data analysis. S.N., K.K. and
R.G-C. prepared samples and designed the experiments. H.S., M.T. S.T., and S.K. wrote and edited the article.

\section{Acknowledgements}

This work was partially supported by KAKENHI from the Japan Society for the Promotion of Science (JSPS) (16K11519) and research fund from Nihon Institute of Medical Science (Ogawa).

\section{References}

1 Zhang X, Liu L,Zhang X, Ma K, Rao Y, Zhao Q and Li F: Analytical methods for brain targeted delivery system in vivo: Perspectives on imaging modalities and microdialysis. Review. J Pharm Biomed Anal 59: 1-12, 2012. PMID: 22088476. DOI: 10.1016/j.jpba.2011.08.042

2 Chang CB, Yoo JJ, Song WS, Kim DJ, Koo K-H and Kim HJ: Transfer of metallic debris from the metal surface of an acetabular cup to artificial femoral heads by scraping: Comparison between alumina and cobalt-chrome heads. J Biomed Mater Res B Appl Biomater 85(1): 204-209, 2008. PMID: 17854069. DOI: 10.1002/jbm.b.30937

3 McPherson A and Cudney B: Optimization of crystallization conditions for biological macromolecules. Acta Crystallogr F Struct Biol Commun 70(Pt 11): 1445-14, 2014. PMID: 25372810. DOI: $10.1107 /$ S2053230X14019670

4 Sugiyama T, Uo M, Wada T, Omagari D, Komiyama K, Noguchi $\mathrm{T}$, Jinbu $\mathrm{Y}$ and Kusama M: Estimation of trace metal elements in oral mucosa specimens by using SR-XRF, PIXE, and XAFS. Biometals 28(1): 11-20, 2015. PMID: 25522792. DOI: 10.1007/s10534-014-9796-6

5 Sterchi Y, Hättenschwiler N and Schwaninger A: Detection measures for visual inspection of X-ray images of passenger baggage. Atten Percept Psychophys 81(5): 1297-1311, 2019. PMID: 30684203. DOI: 10.3758/s13414-018-01654-8

6 Pogue BW and Wilson BC: Optical and X-ray technology synergies enabling diagnostic and therapeutic applications in medicine. Review. J Biomed Opt 23(12): 1-17. PMID: 30350489. DOI: $10.1117 / 1$.JBO.23.12.121610

7 Calabrese EJ: Paradigm lost, paradigm found: The re-emergence of hormesis as a fundamental dose-response model in the toxicological sciences. Environ Pollut 138: 379-412, 2005. PMID: 16098930. DOI: 10.1016/j.envpol.2004.10.001

8 Limoli CL, Giedzinski E, Baure J, Doctrow SR, Rola R and Fike JR: Using superoxide dismutase/catalase mimetics to manipulate the redox environment of neural precursor cells. Radiat Prot Dosimetry 122(1-4): 228-236, 2006. PMID: 17166877. DOI: $10.1093 / \mathrm{rpd} / \mathrm{ncl} 458$

9 Shao C, Aoki M and Furusawa Y: Bystander effect in lymphoma cells vicinal to irradiated neoplastic epithelial cells: Nitric oxide is involved. J Radiat Res 45(1): 97-103, 2004. PMID: 15133296. DOI: $10.1269 /$ jrr.45.97

10 Dong Y, Shen X, He M, Wu Z, Zheng Q, Wang Y, Chen Y, Wu $\mathrm{S}$, Cui J and Zeng Z: Activation of the JNK-c-JUN pathway in response to irradiation facilitates Fas ligand secretion in hepatoma cells and increases hepatocyte injury. J Exp Clin Cancer Res 35(1): 114, 2016. PMID: 27431384. DOI: 10.1186/s 13046-016-0394-z

11 Liu C, Nie J, Wang R and Mao W: The cell cycle $\mathrm{G}_{2} / \mathrm{M}$ block is an indicator of cellular radiosensitivity. Dose Response 17(4): 
1559325819891008, 2019. PMID: 31839758. DOI: 10.1177/ 1559325819891008

12 Andreassi MG, Borghini A, Pulignani S, Baffigi F, Fulgentini L, Koester P, Cresci M, Vecoli C, Lamia D, Russo G, Panetta D, Tripodi M, Gizzi LA and Labate L: Radiobiological effectiveness of ultrashort laser-driven electron bunches: Micronucleus frequency, telomere shortening and cell viability. Radiat Res 186(3): 245-253, 2016. PMID: 27439449. DOI: $10.1667 / \mathrm{RR} 14266.1$

13 Noy Rithidech KN and Bobby R Scott BR: Evidence for radiation hormesis after in vitro exposure of human lymphocytes to low doses of ionizing radiation. Dose Response 6(3): 252-271, 2008. PMID: 18846261. DOI: 10.2203/dose-response.07024.Rithidech

14 Iijima Y, Bandow K, Sano M, Hino S, Kaneko T, Horie N and Sakagami H: In vitro assessment of antitumor potential and combination - Effect of classical and molecular-targeted anticancer drugs. Anticancer Res 39(12): 6673-6684, 2019. PMID: 31810932. DOI: 10.21873/anticanres.13882

15 Sakagami H, Suzuki R, Shirataki Y, Iwama S, Nakagawa M, Suzuki H, Tanaka K, Tamura N and Takeshima H: Re-evaluation of culture condition of PC12 and SH-SY5Y cells based on growth rate and amino acid consumption. In Vivo 31(11): 10891095, 2017. PMID: 29102930. DOI: 10.21873/invivo.11174

16 Sakagami H, Hromchak R and Bloch A: Prevention of phorbol ester receptor down modulation in human myeloblastic leukemia ML-1 cells by differentiation-stimulating serum components. Cancer Res 44: 3330-3335, 1984. PMID: 6331642.

17 Sakagami H, Shi H, Bandow K, Tomomura M, Tomomura A, Horiuchi $M$, Fujisawa $T$ and Oizumi $T$ : Search of neuroprotective polyphenols using the 'overlay' isolation method. Molecules 23(8): 1840, 2018. PMID: 30042342. DOI: $10.3390 /$ molecules 23081840
18 Sakagami H, Tsuji M, Tomomura M, Masuda Y, Iwama S, Nakagawa M, Suzuki H, Tanaka K, Abe T, Tamura N, Tomomura A, Yokose S, Takeshima H, Natori T, Horiuchi M, Fujisawa T, Kiuchi Y, Oguchi K, Yasui T, Oizumi H and Oizumi T: Protection of differentiating neuronal cells from amyloid $\beta$ peptide-induced injury by alkaline extract of leaves of Sasa senanensis Rehder. In Vivo 32(2): 231-239, 2018. PMID: 29475904. DOI: 10.21873/ invivo.11229

19 Lancia A, Becherini C, Detti B, Bottero M, Baki M, Cancelli A, Ferlosio A, Scoccianti S, Sun R, Livi L and Ingrosso G: Radiotherapy for papillary tumor of the pineal region: A systematic review of the literature. Clin Neurol Neurosurg 190: 105646, 2019. PMID: 31896492. DOI: 10.1016/j.clineuro.2019.105646

20 Wujanto C, Choo BA, Tan D, Ilancheran A, Ng J, Low JJH, Shen L, Tang J and Vicky Koh V: Does external beam radiation boost to pelvic lymph nodes improve outcomes in patients with locally advanced cervical cancer? BMC Cancer 19(1): 385 , 2019. PMID: 31023261. DOI: 10.1186/s12885-019-5594-4

21 Liu TI, Yang YC, Chiang WH, Hung CK, Tsai YC, Chiang CS, Lo CL and Chiu HC: Radiotherapy-controllable chemotherapy from reactive oxygen species-responsive polymeric nanoparticles for effective local dual modality treatment of malignant tumors. Biomacromolecules 19(9): 3825-3839, 2018. PMID: 30044907. DOI: 10.1021/acs.biomac.8b00942

22 Wang CR, Mahmood J, Zhang QR, Vedadi A, Warrington J, Ou $\mathrm{N}$, Bristow RG, Jaffray $\mathrm{DA}$ and $\mathrm{Lu} \mathrm{QB}$ : In vitro and in vivo studies of a new class of anticancer molecules for targeted radiotherapy of cancer. Mol Cancer Ther 15(4): 640-650, 2016. PMID: 26921393. DOI: 10.1158/1535-7163.MCT-15-0862

Received January 10, 2020

Revised January 28, 2020

Accepted January 30, 2020 